\title{
A Short Diastereoselective Synthesis of Orthogonally Protected Diamino Succinic Acid Derivatives
}

\author{
Kirsten Zeitler, Wolfgang Steglich ${ }^{*}$ \\ Department Chemie, Ludwig-Maximilians-Universität München, \\ Butenandtstr. 5-13 (Haus F), D-81377 München, Germany \\ wos@cup.uni-muenchen.de
}

\section{List of Content}

General Methods

General Procedures for $\alpha$-chloro glycine derivatives, dimerization and hydrogenation

$\mathrm{S} 2-\mathrm{S} 3$

Experimental Data for dimers and diaminosuccinic acid derivatives 1-5, 8

S3-S6

${ }^{1} \mathrm{H}$ and ${ }^{13} \mathrm{C}$ NMR spectra of dimers and diaminosuccinic acid derivatives 1-5, 8

S7-S24

\section{General Methods}

NMR spectra were recorded at $600.19 \mathrm{MHz}$ and $300.13 \mathrm{MHz}$ using the solvent peak as internal reference $\left(\mathrm{CDCl}_{3}: \delta \mathrm{H} 7.26, \delta \mathrm{C} 77.7\right)$. IR spectra intensities are given as: $\mathrm{s}$ (strong), m (medium), w (weak) and br (broad). All reactions were monitored by thin-layer chromatography. Standard flash chromatography procedures were followed (particle size 40-63 $\mu \mathrm{m}$ ).

Dichloromethane was distilled from $\mathrm{P}_{2} \mathrm{O}_{5}$, and tetrahydrofuran was distilled from potassium/benzophenone. Other solvents were purchased at absolute quality and stored over molecular sieves. Sulfuryl chloride was purchased as a $1 \mathrm{M}$ solution in $\mathrm{CH}_{2} \mathrm{Cl}_{2}$ from Aldrich. All reactions were carried out under an argon atmosphere using oven-dried glassware. All $\alpha$-(ethylthio)glycine derivatives were prepared according to standard procedures. ${ }^{1}$

Hydrogenations with high pressure were conducted either within a Parr hydrogenation apparatus (maximum pressure 6 bar, $500 \mathrm{~mL}$ flask, shaking) or with an autoclave (max. pressure 150 bar, $100 \mathrm{~mL}$ flask, stirring).

${ }^{1}$ (a) Apitz, G.; Steglich, W. Tetrahedron Lett. 1991, 32, 3163-3166. (b) Apitz, G.; Jäger, M.; Jaroch, S.; Kratzel, M.; Schäffeler, L.; Steglich, W. Tetrahedron 1993, 49, 8223-8232. (c) Steglich, W.; Jäger, M.; Jaroch, S.; Zistler, P. Pure Appl. Chem. 1994, 66, 2167-2170. 


\section{General Procedures}

\section{General procedure A: synthesis of $\alpha$-chloroglycine derivatives}

To a solution of the $\alpha$-(ethylthio)glycyl peptide $(1.0 \mathrm{mmol})^{1}$ in $\mathrm{CH}_{2} \mathrm{Cl}_{2}(30 \mathrm{~mL})$ was added a $1 \mathrm{M}$ solution of $\mathrm{SO}_{2} \mathrm{Cl}_{2}(1.1 \mathrm{~mL}, 1.1 \mathrm{mmol})$ in $\mathrm{CH}_{2} \mathrm{Cl}_{2}$ at $0{ }^{\circ} \mathrm{C}$. After $30 \mathrm{~min}$ of stirring, the solvent and all volatile by-products were evaporated (cooling trap), and the resulting residue was dried under high vacuum. The resulting $\alpha$-chloropeptides were used for the next step without further purification.

\section{General procedure B: synthesis of homomeric dimers}

To a solution of the $\alpha$-chloroglycyl peptide $(1.0 \mathrm{mmol})$ and $\mathrm{PPh}_{3}(0.2 \mathrm{mmol})$ in THF $(50 \mathrm{~mL})$ was added $\mathrm{NEt}_{3}(0.15 \mathrm{~mL}, 1.1 \mathrm{mmol})$ in THF $(30 \mathrm{~mL})$ dropwise during $5 \mathrm{~h}$. After continued stirring overnight, petroleum ether $(200 \mathrm{~mL})$ was added and the mixture filtered through Celite ${ }^{\circledR}$. Evaporation of the filtrate in vacuo yielded an oily residue which was purified by column chromatography on silica gel (petroleum ether/EtOAc).

\section{General procedure C: synthesis of heteromeric dimers}

To a solution of an $\alpha$-chloroglycyl peptide $(1.0 \mathrm{mmol})$ in $\mathrm{CH}_{2} \mathrm{Cl}_{2}(40 \mathrm{~mL})$ was added $\mathrm{PPh}_{3}(1.0 \mathrm{mmol})$, and the mixture was stirred at room temperature overnight. Removal of the solvent afforded the phosphonium salt in quantitative yield. The salt was dissolved in THF $(100 \mathrm{~mL})$ and cooled to $-78{ }^{\circ} \mathrm{C}$ (solution I).

A solution of the second $\alpha$-chloroglycyl peptide $(1.5 \mathrm{mmol})$ in THF $(50 \mathrm{~mL})$ was transferred to an addition funnel with cooling $\left(\mathrm{CO}_{2} /\right.$ acetone $)$ and treated with $\mathrm{NEt}_{3}(2.5 \mathrm{mmol})$ at $-78{ }^{\circ} \mathrm{C}$ (solution II).

Solution II was added dropwise at $-78{ }^{\circ} \mathrm{C}$ to the stirred solution I, and the mixture was allowed to rise to room temperature overnight. After addition of petroleum ether and filtration through Celite ${ }^{\circledR}$ the filtrate was concentrated in vacuo. The residue was purified by column chromatography on silica gel (petroleum ether/EtOAc).

\section{General procedure D: homogeneous hydrogenation of glycinate dimers}

For the hydrogenation of $0.15 \mathrm{mmol}$ of a glycinate dimer a solution of $10 \mathrm{~mol} \%$ of the respective $\mathrm{Rh}$-complex in $5 \mathrm{~mL}$ of an absolute and degassed solvent was prepared. After addition of 2 eq of a suitable phosphine ligand (based on Rh-complex) the mixture was stirred $30 \mathrm{~min}$ at room temperature and then this catalyst solution was transferred via cannula to the hydrogenation flask containing the dimer substrate $(\mathrm{c}=$ $0.4 \mathrm{mmol} / \mathrm{mL}$ ) under an argon atmosphere. After 3 cycles of evacuation and $\mathrm{H}_{2}$ refilling the hydrogenation was conducted at the stated $\mathrm{H}_{2}$ pressure and temperature. Upon complete conversion (TLC) the reaction mixture was concentrated in vacuo. To remove catalyst remains the residue was purified by column chromatography on silica gel. 
General procedure E: isomerization of glycinate dimers under basic conditions

$0.83 \mathrm{ml}(8.0 \mathrm{mmol})$ of diethylamine was added to a solution of $1.0 \mathrm{mmol}$ of a gylcine dimer in $100 \mathrm{~mL}$ methanol. The reaction mixture was heated to reflux. Upon reaching of a 1:1-mixture of both isomers (TLC) the reaction was terminated and the solution was concentrated under reduced pressure, diluted with $50 \mathrm{~mL}$ of EtOAc and was washed $2 \times$ with $30 \mathrm{~mL}$ of a $1.1 \mathrm{M}$ solution of $\mathrm{KHSO}_{4}, 30 \mathrm{~mL}$ water and $30 \mathrm{~mL}$ brine. After drying with $\mathrm{MgSO}_{4}$ and concentration in vacuo the residue was purified by column chromatography on silica gel.

\section{Experimental Data}

2,3-Bis $\left(N, N^{\prime}\right.$-tert-butyloxycarbonylamino)maleic acid dimethyl ester $[(Z)-1] .^{2}$ following general procedure B: yield 96\%, colorless foam. UV $\left(\mathrm{CH}_{3} \mathrm{CN}\right) \lambda_{\max }(\varepsilon) 270.0 \mathrm{~nm}(10816) ; \mathrm{IR}(\mathrm{KBr}) \tilde{\mathrm{v}} 3411$ (m, br), 2981 (m), 1723 (s), 1627 (s), 1494 (m), 1436 (m), 1393 (m), 1369 (s), 1326 (m), 1242 (s), 1154 (s), 1049 (w), 1022 (w), $866(\mathrm{w}), 831(\mathrm{w}), 772(\mathrm{w}), 746(\mathrm{w}), 602(\mathrm{w}) \mathrm{cm}^{-1}$; ${ }^{1} \mathrm{H}$ NMR (300 MHz, $\left.\mathrm{CDCl}_{3}\right) \delta 6.81$ (br s, 2H, NH), 3.79 (s, 6H), 1.44 (s, 18H); ${ }^{1} \mathrm{H}$ NMR (300 MHz, acetone- $\left.d_{6}\right) \delta 7.85$ (br s, 2H, NH), $3.62(\mathrm{~s}, 6 \mathrm{H})$, $1.38(\mathrm{~s}, 18 \mathrm{H}) ;{ }^{13} \mathrm{C} \mathrm{NMR}\left(\mathrm{CDCl}_{3}, 75 \mathrm{MHz}\right) \delta 164.4,153.0,82.9,53.4,28.7 ;{ }^{3} \mathrm{MS}$ (ESI) $\mathrm{m} / \mathrm{z}(\%) 772(1)$ $[2 \mathrm{M}+\mathrm{H}+\mathrm{Na}]^{+}, 771$ (4) $[2 \mathrm{M}+\mathrm{Na}]^{+}, 602(16), 601$ (20), 557 (20), 486 (20), 415 (41), 414 (25), 399 (3) $\left[\mathrm{MH}_{2}+\mathrm{Na}\right]^{+}, 398$ (17) $[\mathrm{MH}+\mathrm{Na}]^{+}, 397$ (100) $[\mathrm{M}+\mathrm{Na}]^{+}, 341$ (12), 303 (8), 285 (4); HR ESI MS m/z found 397.1599, calcd for $[\mathrm{M}+\mathrm{Na}]^{+} 397.1587$; anal. calcd for $\mathrm{C}_{16} \mathrm{H}_{26} \mathrm{~N}_{2} \mathrm{O}_{8}: \mathrm{C}, 51.33 ; \mathrm{N}, 7.48 ; \mathrm{H}, 7.00$; found: $\mathrm{C}$, 50.93; N, 7.39; H, 7.01.

2,3-Bis( $N, N^{\prime}$-tert-butyloxycarbonylamino)fumaric acid dimethyl ester [(E)-1]. following general procedure E: yield 43\%, colorless foam. UV $\left(\mathrm{CH}_{3} \mathrm{CN}\right) \lambda_{\max }(\varepsilon) 270.6 \mathrm{~nm}(12815)$; IR (KBr) $\tilde{v} 3435$ (s), 2981 (m), 1711 (s), 1627 (m), 1484 (m), 1436 (m), 1370 (m), 1285 (s), 1252 (s), 1152 (s), 1054 (w), 1006 (w), $871(\mathrm{w}), 815$ (w), $778(\mathrm{w}), 742(\mathrm{w}), 595$ (w) cm ${ }^{-1} ;{ }^{1} \mathrm{H}$ NMR (300 MHz, $\mathrm{CDCl}_{3}$ ) $\delta 7.68$ (br s, 2H, NH), $3.82(\mathrm{~s}, 6 \mathrm{H}), 1.43(\mathrm{~s}, 18 \mathrm{H}) .{ }^{1} \mathrm{H}$ NMR $\left(300 \mathrm{MHz}\right.$, acetone- $\left.d_{6}\right) \delta 8.44(\mathrm{br} \mathrm{s}, 2 \mathrm{H}, \mathrm{NH}), 3.70(\mathrm{~s}, 6 \mathrm{H})$, 1.39 (s, 18H,); ${ }^{13} \mathrm{C}$ NMR $\left(75 \mathrm{MHz}, \mathrm{CDCl}_{3}\right) \delta 165.3,152.9,81.7,52.5,28.0 ;{ }^{3} \mathrm{MS}$ (ESI) $\mathrm{m} / \mathrm{z}(\%) 773(6)$ $[2 \mathrm{MH}+\mathrm{Na}]^{+}, 772(17)[2 \mathrm{M}+\mathrm{H}+\mathrm{Na}]^{+}, 771(47)[2 \mathrm{M}+\mathrm{Na}]^{+}, 538(2), 413(6), 412(2), 399$ (3) $\left[\mathrm{MH}_{2}+\mathrm{Na}\right]^{+}$, 398 (11) $[\mathrm{MH}+\mathrm{Na}]^{+}, 397(100)[\mathrm{M}+\mathrm{Na}]^{+}, 285$ (5); HR ESI MS m/z found 397.1599, calcd for $[\mathrm{M}+\mathrm{Na}]^{+}$397. 1608; anal. calcd for $\mathrm{C}_{16} \mathrm{H}_{26} \mathrm{~N}_{2} \mathrm{O}_{8} \mathrm{C}, 51.33 ; \mathrm{N}, 7.48 ; \mathrm{H}, 7.00$, found: $\mathrm{C}$ 51.07; N 7.40; H 7.11.

\footnotetext{
${ }^{2}$ see ref 11 (Schumann, S.; Zeitler, K.; Jäger, M.; Polborn, K.; Steglich, W. Tetrahedron 2000, 56, 4187-4195).

${ }^{3}$ The signal for the $\mathrm{C}-\mathrm{C}$ double bond is not visable.
} 
(anti)-(2R*,3S*)-Dimethyl $N, N^{\prime}$-di-tert-butyloxycarbonyl-3-aminoaspartate [(anti)-2]. ${ }^{4}$ following general procedure $\mathbf{D}$ using $(Z)-\mathbf{1}\left([\mathrm{Rh}(\mathrm{COD}) \mathrm{Cl}]_{2} / \mathrm{dppf} ; 90\right.$ bar $\left.\mathrm{H}_{2} ; 80{ }^{\circ} \mathrm{C}, 24 \mathrm{~h}\right)$ : yield $92 \%$, colorless solid. IR (KBr) v 3431 (s, br), 2980 (m), 2934 (w), 1760 (s), 1716 (s, sh), 1691 (s), 1636 (w), 1516 (m), 1456 (w), 1440 (w), 1394 (w), 1369 (s), 1319 (m), 1305 (m), 1251 (m), 1216 (m), 1169 (s), 1060 (m), 1019 (m), $922(\mathrm{w}), 902$ (w), 853 (w), $822(\mathrm{w}), 781(\mathrm{w}), 766(\mathrm{w}) \mathrm{cm}^{-1}$; ${ }^{1} \mathrm{H}$ NMR (300 MHz, $\left.\mathrm{CDCl}_{3}\right) \delta 5.43$ (br s, 2H, $\mathrm{NH}), 4.83$ (br d, $J=7.4 \mathrm{~Hz}, 2 \mathrm{H}), 3.75(\mathrm{~s}, 6 \mathrm{H}), 1.45$ (s, 18H); ${ }^{13} \mathrm{C} \mathrm{NMR}\left(150 \mathrm{MHz}, \mathrm{CDCl}_{3}\right) \delta 170.4,156.3$, 81.3, 56.5 , 53.5, 28.9; MS (ESI) m/z (\%) 775 (2) [2M+Na $]^{+}, 653$ (2), 597 (14), 436 (9), 415 (4) [M+K] $]^{+}$, 399 (71) $[\mathrm{M}+\mathrm{Na}]^{+}, \quad 377$ (1) $[\mathrm{M}+\mathrm{H}]^{+}, 277$ (34) $\left[\mathrm{M}+\mathrm{H}-\mathrm{C}_{4} \mathrm{H}_{8}-\mathrm{CO}_{2}\right]^{+}, \quad 221$ (100) $\left[\mathrm{M}+\mathrm{H}-2 \mathrm{C}_{4} \mathrm{H}_{8}-\mathrm{CO}_{2}\right]^{+}$; HR ESI MS $m / z$ found 399.1735 , calcd for $[\mathrm{M}+\mathrm{Na}]^{+} 399.1743$.

(syn)-(2R*,3R*)-Dimethyl $N, N^{\prime}$-di-tert-butyloxycarbonyl-3-aminoaspartate [(syn)-2]. ${ }^{4}$ following general procedure D using $(E)-\mathbf{1}\left([\mathrm{Rh}(\mathrm{COD}) \mathrm{Cl}]_{2} / \mathrm{dppf} ; 90\right.$ bar $\left.\mathrm{H}_{2} ; 80{ }^{\circ} \mathrm{C}, 24 \mathrm{~h}\right)$ : yield $90 \%$ colorless solid. IR (KBr) $\tilde{v} 3436$ (s, br), 2980 (w), 1751 (m), 1718 (s), 1631 (m), 1514 (m), 1439 (w), 1370 (m, sh), 1255 (m), 1166 (s), 1053 (w), 1029 (w), 860 (w) cm ${ }^{-1} ;{ }^{1} \mathrm{H}$ NMR (300 MHz, CDCl $) \delta 5.33$ (br d, J=7.2 Hz, 2H), 4.79 (br d, $J=8.2 \mathrm{~Hz}, 2 \mathrm{H}), 3.78(\mathrm{~s}, 6 \mathrm{H}), 1.42(\mathrm{~s}, 18 \mathrm{H}) ;{ }^{13} \mathrm{C}$ NMR $\left(150 \mathrm{MHz}, \mathrm{CDCl}_{3}\right) \delta 170.7,155.5$, 81.1, 56.0, 53.7, 28.9; MS (ESI) $\mathrm{m} / z(\%) 775$ (36) $[2 \mathrm{M}+\mathrm{Na}]^{+}, 597$ (7), 436 (8), 415 (4) $[\mathrm{M}+\mathrm{K}]^{+}$, 399 (39) $[\mathrm{M}+\mathrm{Na}]^{+}, 377$ (7) $[\mathrm{M}+\mathrm{H}]^{+}, 321$ (2) $\left[\mathrm{M}+\mathrm{H}-\mathrm{C}_{4} \mathrm{H}_{8}\right]^{+}, 277$ (14) $\left[\mathrm{M}+\mathrm{H}_{-} \mathrm{C}_{4} \mathrm{H}_{8}-\mathrm{CO}_{2}\right]^{+}, \quad 221$ (100) $\left[\mathrm{M}+\mathrm{H}-2 \mathrm{C}_{4} \mathrm{H}_{8}-\mathrm{CO}_{2}\right]^{+} ; \mathrm{HR}$ ESI MS $\mathrm{m} / z$ found 399.1747 , calcd for $[\mathrm{M}+\mathrm{Na}]^{+} 399.1743$.

2,3-Bis( $N, N$ '-tert-butyloxycarbonyl-L-alanylamino)maleic acid dimethyl ester [(Z)-3]. following general procedure B: yield $89 \%$, colorless foam. UV $\left(\mathrm{CH}_{3} \mathrm{CN}\right) \lambda_{\max }(\varepsilon) 278.4 \mathrm{~nm}(16299)$; IR $(\mathrm{KBr})$ v 3371 (m, br) 2981 (m), 2954 (m), 1697 (s, br), 1631 (m), 1513 (s), 1456 (m), 1437 (m), 1334 (m), 1368 (s), 1334 (s, br), 1304 (s, br), 1250 (m), 1204 (m), 1166 (s), 1093 (w), 1071 (m), 1053 (w), 1024 (w), 967 (w), 914 (w), 859 (w), 780 (w), 759 (w), 597 (w), 522 (w), 462 (w) cm ${ }^{-1} ;{ }^{1} \mathrm{H}$ NMR (300 MHz, $\mathrm{CDCl}_{3}$ ) $\delta 8.76($ br s, 2H, NH), $5.16($ br s, 2H, NH), 4.28 (br s, 2H), $3.80(\mathrm{~s}, 6 \mathrm{H}), 1.44(\mathrm{~s}, 18 \mathrm{H})$, $1.40(\mathrm{~d}, J=7.2 \mathrm{~Hz}, 6 \mathrm{H}) ;{ }^{13} \mathrm{C}$ NMR $\left(75 \mathrm{MHz}, \mathrm{CDCl}_{3}\right) \delta 172.1,164.2,156.2,123.7,81.3,53.6,51.1,29.0$, 18.5 ; MS (ESI) m/z (\%) 1055 (5) [2M+Na] $]^{+}, 933$ (5), 877 (5), 801 (13), 779 (21), 555 (15) [M+K] $]^{+}, 539$ (30) $[\mathrm{M}+\mathrm{Na}]^{+}, \quad 534 \quad(100) \quad\left[\mathrm{M}+\mathrm{NH}_{4}\right]^{+}, \quad 517(3) \quad[\mathrm{M}+\mathrm{H}]^{+}, \quad 417(13) \quad\left[\mathrm{M}+\mathrm{H}_{-} \mathrm{C}_{4} \mathrm{H}_{8}-\mathrm{CO}_{2}\right]^{+}$, $361(17)\left[\mathrm{M}+\mathrm{H}-2 \mathrm{C}_{4} \mathrm{H}_{8}-\mathrm{CO}_{2}\right]^{+}, 100$ (10); HR ESI MS $m / z$ found 534.2774, calcd for $\left[\mathrm{M}+\mathrm{NH}_{4}\right]^{+} 534.2775$; anal. calcd for $\mathrm{C}_{22} \mathrm{H}_{36} \mathrm{~N}_{4} \mathrm{O}_{10} \times 3 / 4 \mathrm{H}_{2} \mathrm{O}$ C, 49.85; N, 10.57; H, 7.13, found: C 49.63; N 10.29; H 7.03.

(anti)-(2R*,3S*)-2,3-Bis(tert-butyloxycarbonyl-L-alanylamino)succinic acid dimethyl ester [(anti)-4]. ${ }^{5}$ following general procedure $\mathbf{D}$ using $(Z)-3$ ([Rh(COD)Cl $]_{2} / \mathrm{dppf} ; 95$ bar $\mathrm{H}_{2} ; 80{ }^{\circ} \mathrm{C}, 24 \mathrm{~h}$ ): yield $93 \%$, colorless solid. IR (KBr) $\tilde{v} 3423$ (m, br), 2980 (m), 2935 (w), 1749 (s), 1689 (s, sh), 1514 (s), 1454 (m, sh),

\footnotetext{
${ }^{4}$ see ref 10a (Fernandez-Megia, E.; Paz, M. M.; Sardina, F. J. J. Org. Chem. 1994, 59, 7643-7652).

${ }^{5}$ For more complex systems the use of the "succinic acid" based nomenclature seems to be more practical (alternatively, here: (anti)-( $\left.2 R^{*}, 3 S^{*}\right)$-Dimethyl ( $N, N^{\prime}$-di-tert-butyloxycarbonyl-1-alanyl)-3-aminoaspartate (anti)-4).
} 
1392 (m), 1368 (m), 1250 (m, sh), 1216 (m), 1169 (s), 1094 (w), 1070 (w), 1051 (w), 1025 (w), 962 (w),

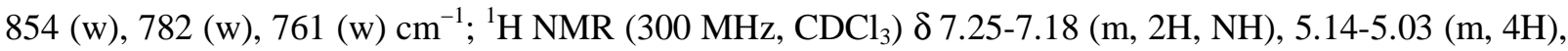
4.19-4.03 (m, 2H), 3.723 .70 (each s, 3H), 1.42, 1.41 (each s, 9H), $1.24(\mathrm{~d}, J=7.2 \mathrm{~Hz}, 6 \mathrm{H},) ;{ }^{6}{ }^{13} \mathrm{C} \mathrm{NMR}$ $\left(75 \mathrm{MHz}, \mathrm{CDCl}_{3}\right) \delta 174.0,169.8,156.3,156.0,81.1,80.7,54.7,54.2,53.5\left(\mathrm{OCH}_{3}\right), 51.5,51.1,28.9$, $19.0,18.7^{6} \mathrm{MS}(\mathrm{ESI}) \mathrm{m} / \mathrm{z}(\%) 1076(1)[2 \mathrm{M}+\mathrm{K}]^{+}, 1060(20)[2 \mathrm{M}+\mathrm{Na}]^{+}, 1055$ (1) $\left[\mathrm{M}+\mathrm{NH}_{4}\right]^{+}, 802(17)$, $780(20), 614(4), 558(2)[\mathrm{M}+\mathrm{K}]^{+}, 541(79)[\mathrm{M}+\mathrm{Na}]^{+}, 536(6)\left[\mathrm{M}+\mathrm{NH}_{4}\right]^{+}, 519(100)[\mathrm{M}+\mathrm{H}]^{+}, 419(15)$ $\left[\mathrm{M}+\mathrm{H}-\mathrm{C}_{4} \mathrm{H}_{8}-\mathrm{CO}_{2}\right]^{+}, 363$ (3) $\left[\mathrm{M}+\mathrm{H}-2 \mathrm{C}_{4} \mathrm{H}_{8}-\mathrm{CO}_{2}\right]^{+}$; HR ESI MS m/z found 519.2695, calcd for $[\mathrm{M}+\mathrm{H}]^{+}$ 519.2666.

[2-(N-Benzyloxycarbonylamino)-3-( $N$-tert-butyloxycarbonylamino)-maleoyl]-4-tert-butylester-1-methyl ester [(Z)-8]. following general procedure $\mathbf{C}$ : yield $61 \%$, colorless foam. UV $\left(\mathrm{CH}_{3} \mathrm{CN}\right)$ $\lambda_{\max }$ (ع) $270.5 \mathrm{~nm}$ (15297); IR (KBr) $\tilde{v} 3435$ (s, br), 2981 (m), 1745 (s), 1740 (s), 1627 (m), 1496 (m), 1437 (m, sh), 1394 (w), 1369 (m), 1329 (m), 1247 (s, sh), 1152 (s), 1048 (w), 846 (w), 740 (w), 699 (w) $\mathrm{cm}^{-1}$; ${ }^{1} \mathrm{H}$ NMR (300 MHz, $\mathrm{CDCl}_{3}$ ) $87.37-7.35$ (m, 6H), 6.76 (br s, 1H), 5.15 (s, 2H), 3.77 (br s, 3H), 1.51, 1.46 (each s, 9H); ${ }^{13} \mathrm{C}$ NMR $\left(75 \mathrm{MHz}, \mathrm{CDCl}_{3}\right.$ ) $\delta 164.5,162.7,154.0,153.1,136.1,129.3,129.1,129.0$, $84.1,82.8,68.6,53.2,28.9,28.5 ;^{7} \mathrm{MS}(\mathrm{ESI}) \mathrm{m} / z(\%) 473$ (1) $[\mathrm{M}+\mathrm{Na}]^{+}, 451$ (23) $[\mathrm{M}+\mathrm{H}]^{+}, 395(23)$ $\left[\mathrm{M}+\mathrm{H}-\mathrm{C}_{4} \mathrm{H}_{8}\right]^{+}, 351$ (3) $\left[\mathrm{M}+\mathrm{H}-\mathrm{C}_{4} \mathrm{H}_{8}-\mathrm{CO}_{2}\right]^{+}, 339$ (56), 295 (12) $\left[\mathrm{M}+\mathrm{H}-2 \mathrm{C}_{4} \mathrm{H}_{8}-\mathrm{CO}_{2}\right]^{+}, 294$ (31), 251 (7) $\left[\mathrm{M}+\mathrm{H}-2 \mathrm{C}_{4} \mathrm{H}_{8}-2 \mathrm{CO}_{2}\right]^{+}, 91$ (100); HR ESI MS $m / z$ found . 451.2106, calcd for $[\mathrm{M}+\mathrm{H}]^{+} 451.2080$.

\section{[2-( $N$-Benzyloxycarbonylamino)-3-( $N$-tert-butyloxycarbonylamino)-fumaroyl]-4-tert-butylester-}

1-methyl ester $[(\boldsymbol{E})-8]$. following general procedure $\mathbf{E}$ : yield $52 \%$, colorless foam. UV $\left(\mathrm{CH}_{3} \mathrm{CN}\right)$ $\lambda_{\max } 268.5$ nm; IR (KBr) v 3430 (s, br), 2980 (w, sh), 1740 (s), 1625 (m), 1483 (m, sh), 1370 (m), 1329 (m), 1224 (s), 1148 (s), 1050 (s), 743 (w), 699 (w), 468 (w) cm ${ }^{-1} ;{ }^{1} \mathrm{H}$ NMR (300 MHz, $\mathrm{CDCl}_{3}$ ) $\delta$ 7.37-7.34 (m, 6H), 5.14 (s, 2H), 4.70 (br s, 1H), 3.77 (br s, 3H), 1.47, 1.46 (each s, 9H); ${ }^{13} \mathrm{C} \mathrm{NMR} \mathrm{(150} \mathrm{MHz,} \mathrm{CDCl}_{3}$ ) $\delta 166.9,163.0,155.3,152.3,136.5,129.2,129 ., 129.0,84.5,82.6,68.2,53.1\left(\mathrm{OCH}_{3}\right), 28.7,28.5 ;{ }^{7} \mathrm{MS}$ (ESI) $\mathrm{m} / z(\%) 940$ (7) [2M+K] $]^{+}, 924$ (54) [2M+Na], 696 (9), 570 (13), 525 (16), 514 (19), 505 (25), 489 (45) $[\mathrm{M}+\mathrm{K}]^{+}, 473(100)[\mathrm{M}+\mathrm{Na}]^{+}, 468(62)\left[\mathrm{M}+\mathrm{NH}_{4}\right]^{+}$; HR ESI MS $m / z$ found 451.2103, calcd for $[\mathrm{M}+\mathrm{H}]^{+}$ 451.2080 .

(anti)-(2R*,3S*)-[2-( $N$-Benzyloxycarbonylamino)-3-( $N$-tert-butyloxycarbonylamino)-succinoyl]4-tert-butylester-1-methyl ester [(anti)-5]. following general procedure $\mathbf{D}$ using (Z)-8 ( $[\mathrm{Rh}(\mathrm{COD}) \mathrm{Cl}]_{2} / \mathrm{dppf} ; 90$ bar $\mathrm{H}_{2} ; 80{ }^{\circ} \mathrm{C}, 24 \mathrm{~h}$ ): yield $99 \%$ colorless oil. IR (KBr) $\tilde{\mathrm{v}} 3370(\mathrm{~m}), 3066(\mathrm{w})$, 2979 (m, sh), 2935 (m), 1724 (s, br), 1587 (w), 1505 (s), 1456 (m), 1438 (m), 1394 (m), 1368 (s), 1348 (m), 1301 (m), 1248 (s), 1218 (s), 1155 (s), 1061 (m), 1028 (m), 914 (w), 868 (w), 845 (w), 756 (m, sh),

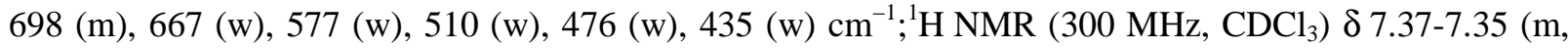

\footnotetext{
${ }^{6}$ Both strands show only partially separated signals in the ${ }^{1} \mathrm{H}$ NMR and ${ }^{13} \mathrm{C}$ NMR spectra.

${ }^{7}$ The signals for the tetrasubstituted double bond are not detectable.
} 
5H), 5.85 (br s, 1H), 5.48 (br s, 1H), $5.13(\mathrm{~s}, 2 \mathrm{H}), 4.89$ (dd, $J=8.3 \mathrm{~Hz}$ und $J=2.8 \mathrm{~Hz}, 1 \mathrm{H}, 4.71$ (br d, $J=5.9 \mathrm{~Hz}, 1 \mathrm{H}), 3.74$ (br s, 3H), 1.46, 1.45 (each s, 9H); ${ }^{13} \mathrm{C} \mathrm{NMR}\left(75 \mathrm{MHz}, \mathrm{CDCl}_{3}\right) \delta 170.2,168.4$, $7.0,156.5136 .8,129.2,129.0,128.9,84.2,81.2,68.0,57.4,57.0,53.3,28.9,28.5$; MS (ESI) $m / z(\%) 491(48)[\mathrm{M}+\mathrm{K}]^{+}, 475(53)[\mathrm{M}+\mathrm{Na}]^{+}, 470(46)\left[\mathrm{M}+\mathrm{NH}_{4}\right]^{+}, 453(39)[\mathrm{M}+\mathrm{H}]^{+} ; \mathrm{HR}$ ESI MS $\mathrm{m} / \mathrm{z}$ found 475.2080, calcd for $[\mathrm{M}+\mathrm{Na}]^{+} 475.2056$.

(syn)-(2R*,3R*)-[2-( $N$-Benzyloxycarbonylamino)-3-( $N$-tert-butyloxycarbonylamino)-succinoyl]4-tert-butylester-1-methyl ester [(syn)-5]. following general procedure $\mathbf{D}$ using (E)-8 $\left([\mathrm{Rh}(\mathrm{COD}) \mathrm{Cl}]_{2} / \mathrm{dppf} ; 90\right.$ bar $\left.\mathrm{H}_{2} ; 80{ }^{\circ} \mathrm{C}, 24 \mathrm{~h}\right)$ : yield $43 \%$ colorless oil. ${ }^{1} \mathrm{H} \mathrm{NMR}\left(300 \mathrm{MHz}, \mathrm{CDCl}_{3}\right)$ $\delta 7.35-7.32(\mathrm{~m}, 5 \mathrm{H}), 5.54$ (br d, $J=9.3 \mathrm{~Hz}, 1 \mathrm{H}), 5.29$ (br d, $J=7.6 \mathrm{~Hz}, 1 \mathrm{H}), 5.13,5.06(2 \mathrm{~d}, J=13.4 \mathrm{~Hz}$, $2 \mathrm{H}), 4.86(\mathrm{~d}, J=7.7 \mathrm{~Hz}, 1 \mathrm{H}), 4.67(\mathrm{br} \mathrm{d}, J=6.9 \mathrm{~Hz}, 1 \mathrm{H}), 3.76$ (br s, 3H), 1.45, 1.42 (each s, 9H); ${ }^{13} \mathrm{C} \mathrm{NMR}\left(75 \mathrm{MHz}, \mathrm{CDCl}_{3}\right) \delta 170.9,168.9,156.3,155.6,136.8,129.2,128.9,128.8,84.4,81.1,68.0,56.5$, 53.6, 28.9, 28.5; MS (ESI) $m / z(\%) 927$ (16) [2M+Na] $]^{+}, 745$ (6), 629 (10), 585 (13), 525 (16), 505 (38), $491(15)[\mathrm{M}+\mathrm{K}]^{+}, 475(100)[\mathrm{M}+\mathrm{Na}]^{+}, 453(23)[\mathrm{M}+\mathrm{H}]^{+}, 437(38), 341$ (52), $296(19), 102$ (4); HR ESI MS $m / z$ found 475. 2072, calcd for $[\mathrm{M}+\mathrm{Na}]^{+} 475.2056$. 


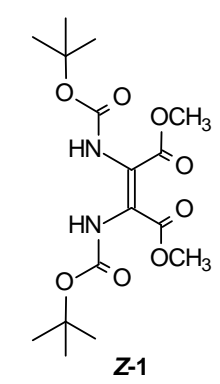

7.85

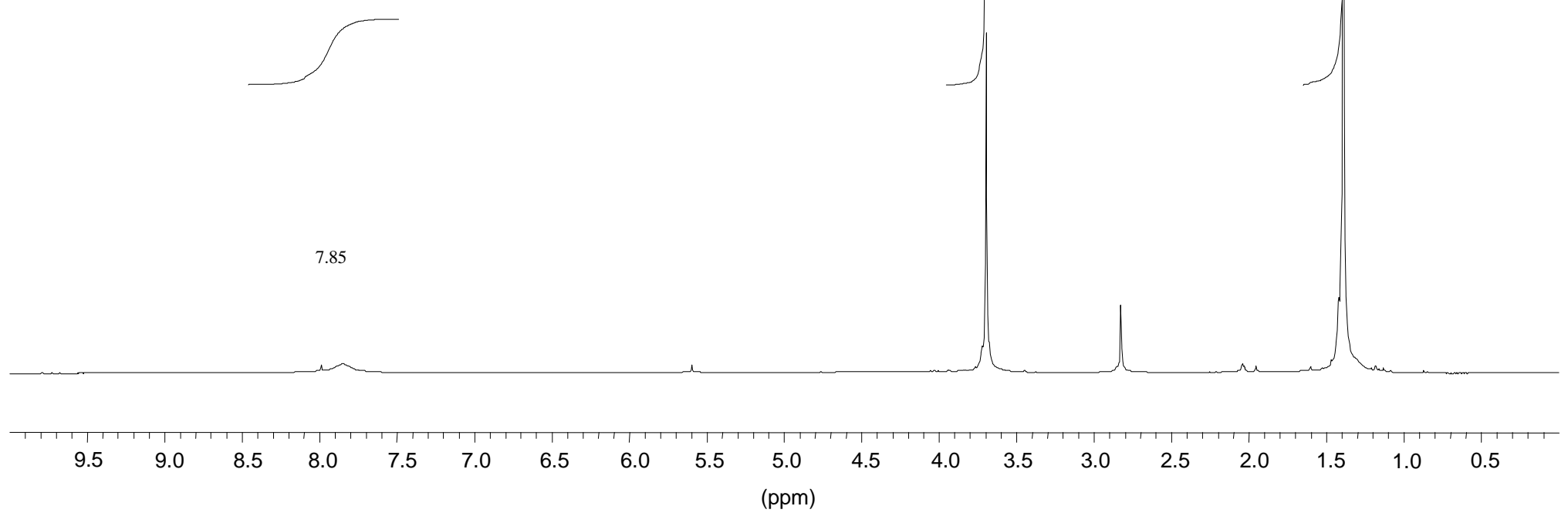

(acetone $\left.-d_{6}\right)$ 

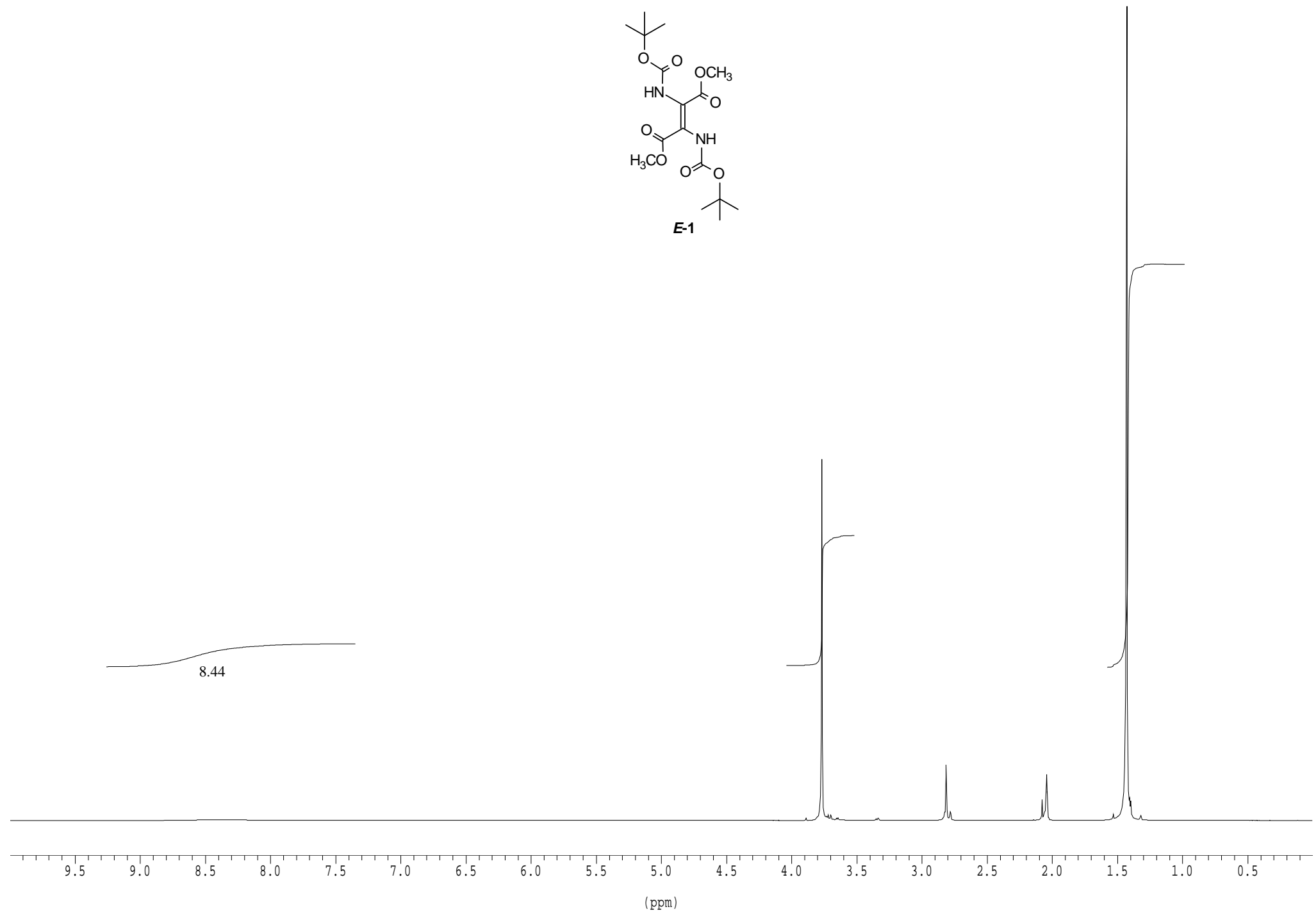

(acetone- $d_{6}$ ) 


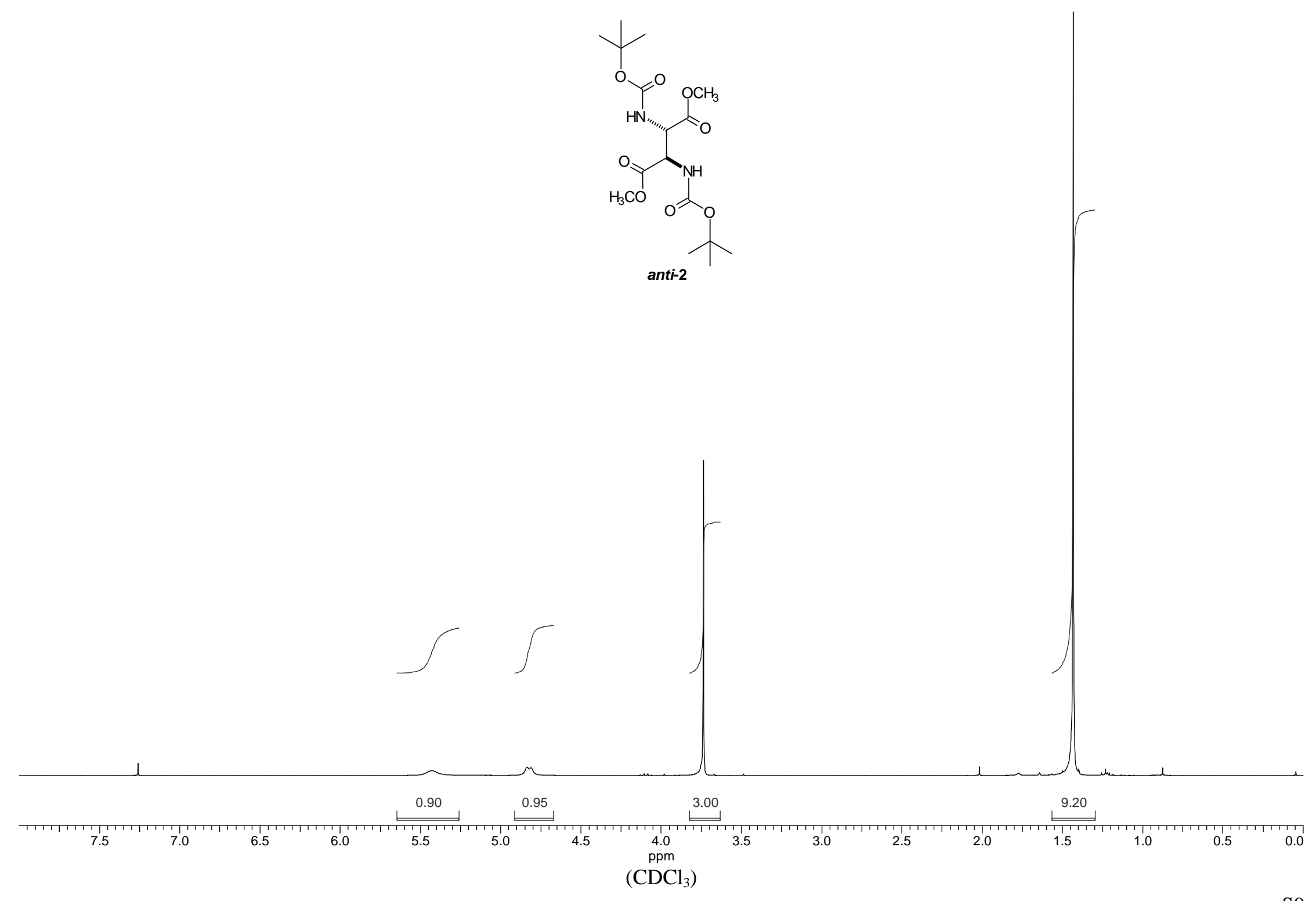




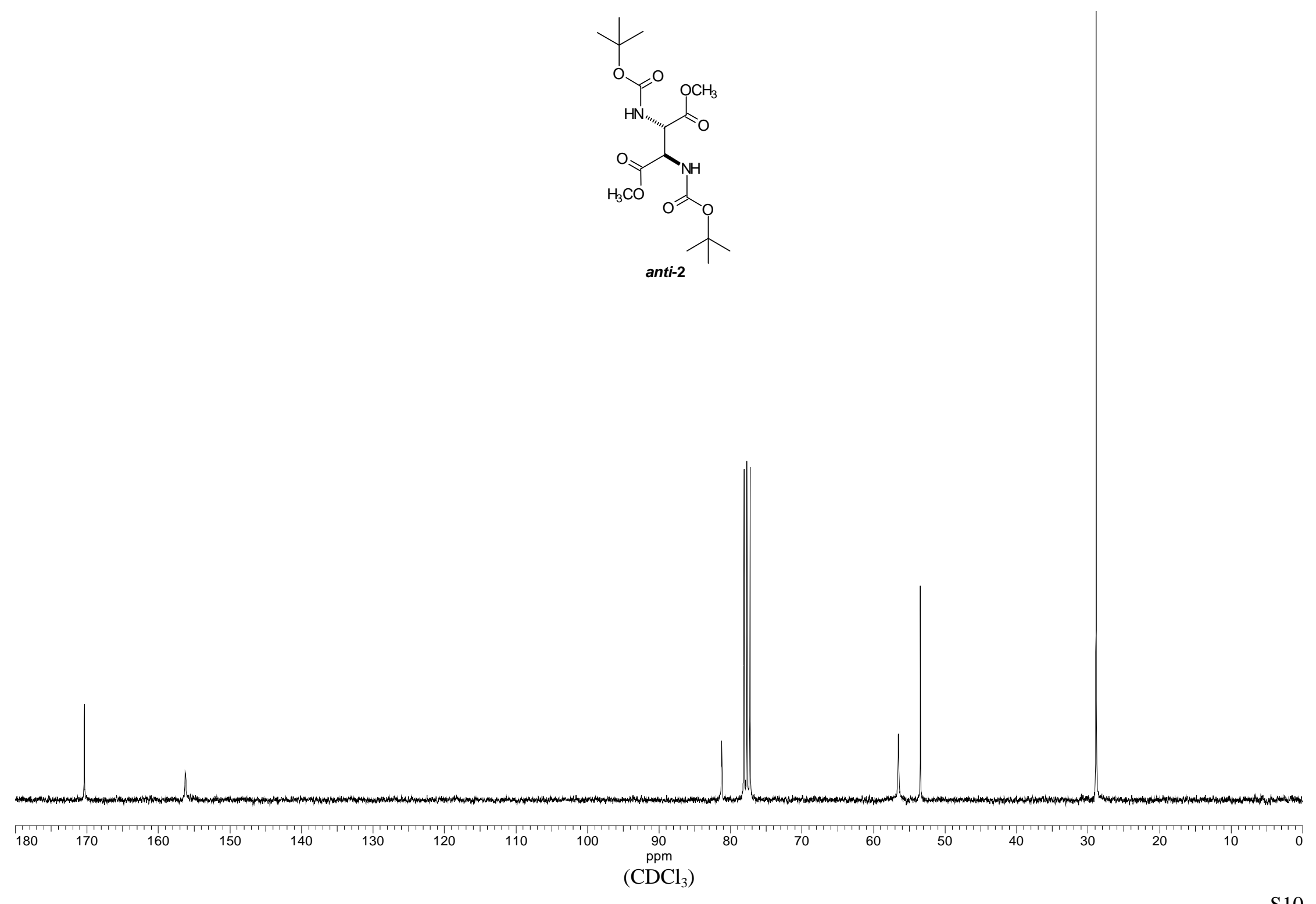




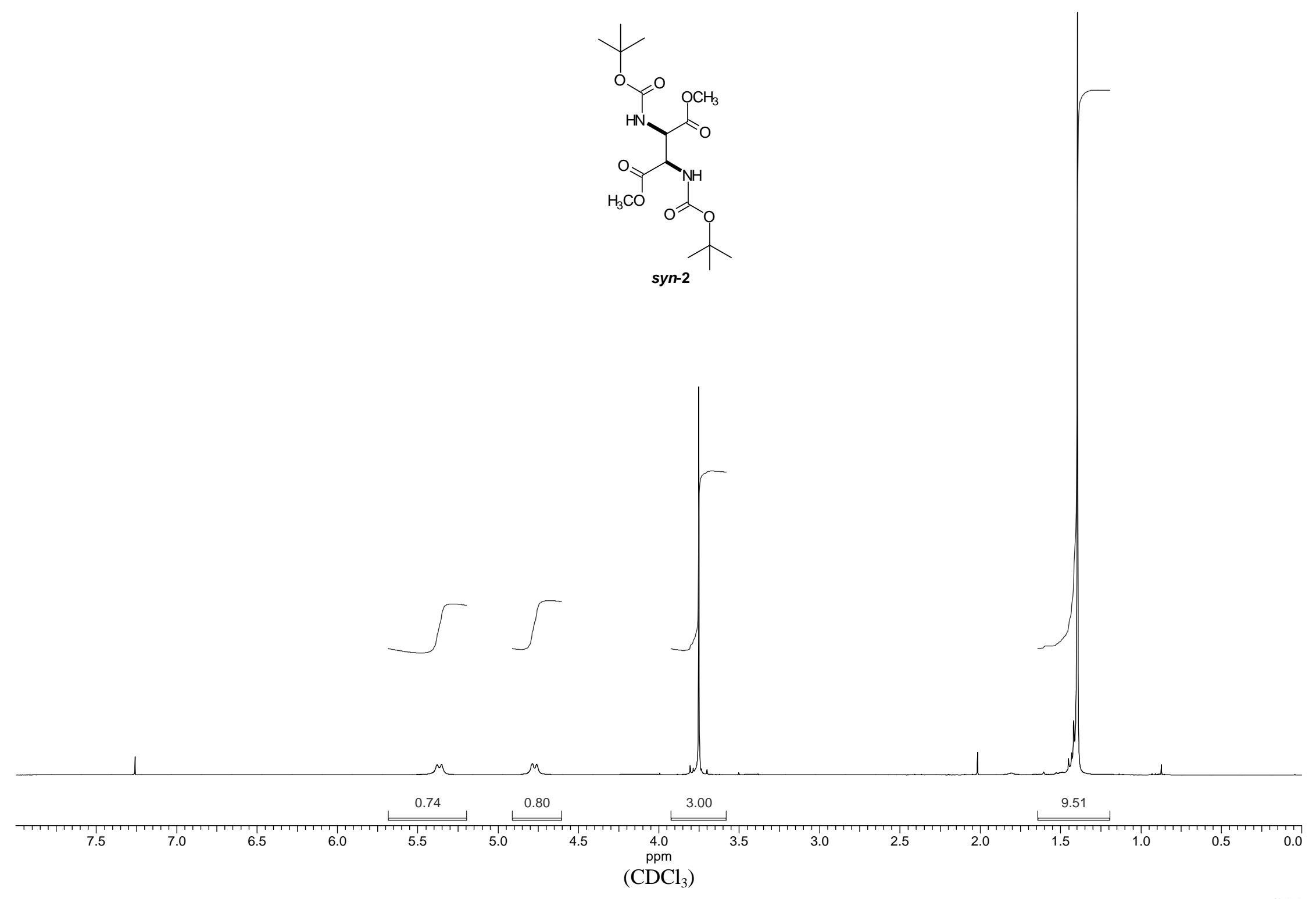




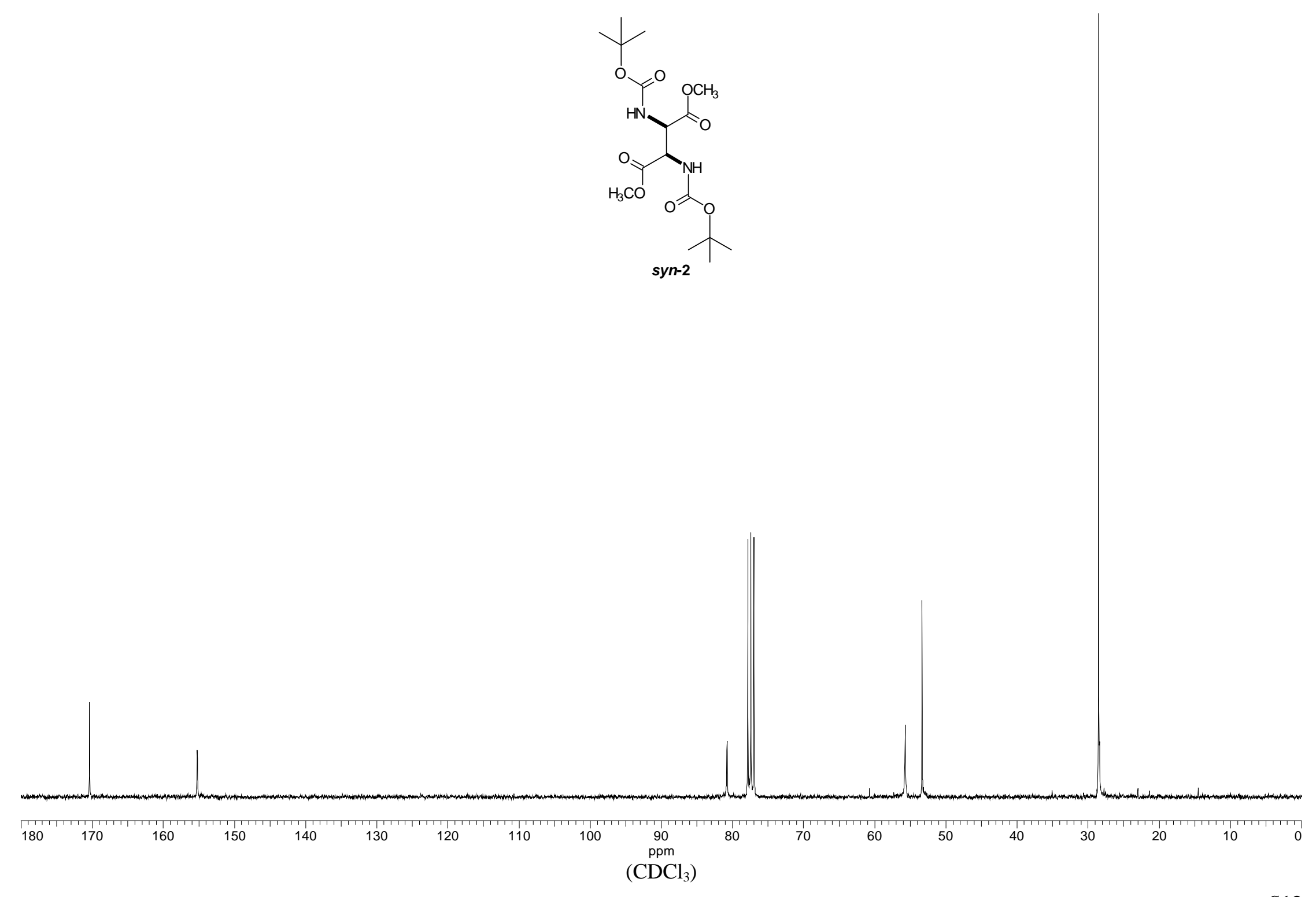




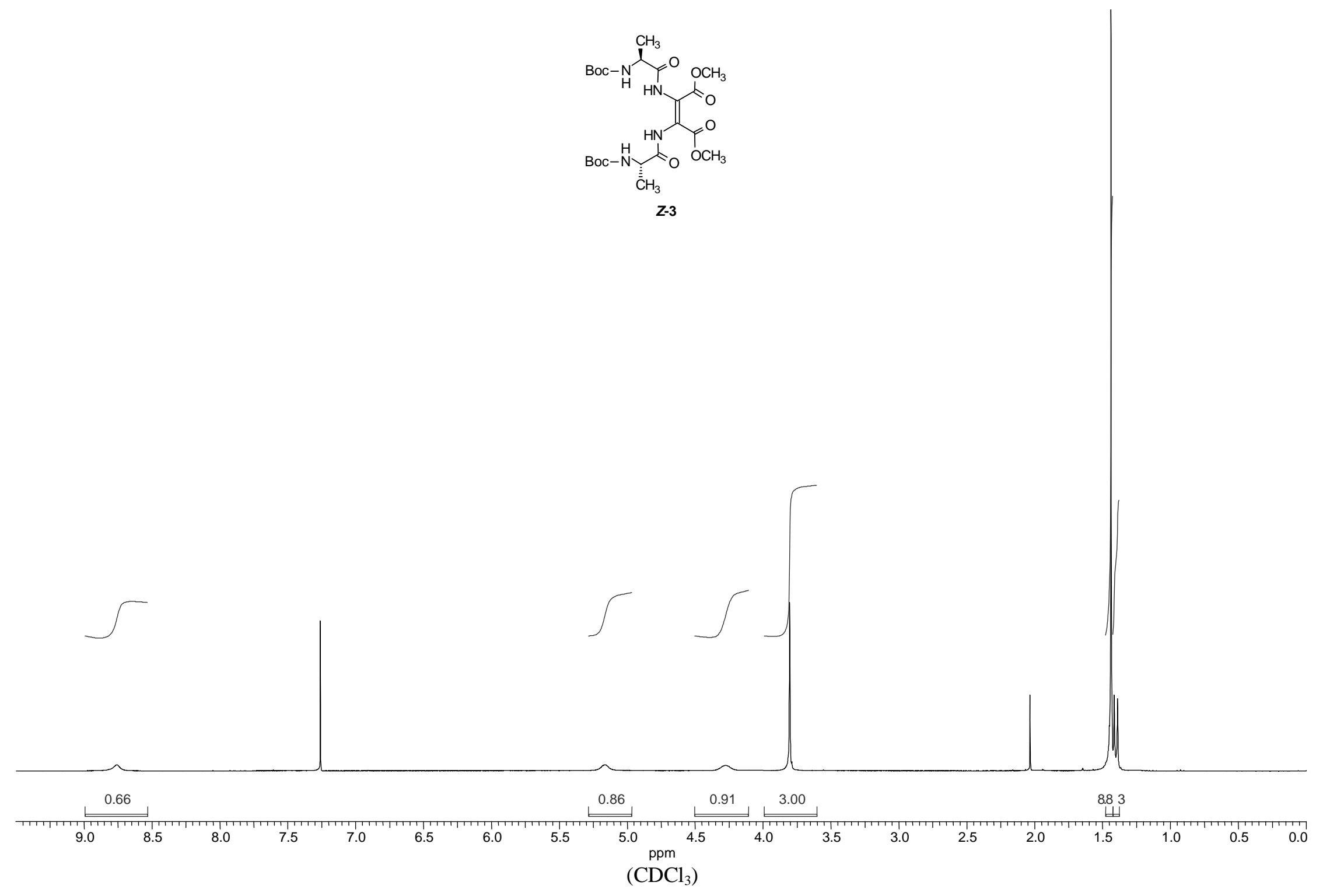




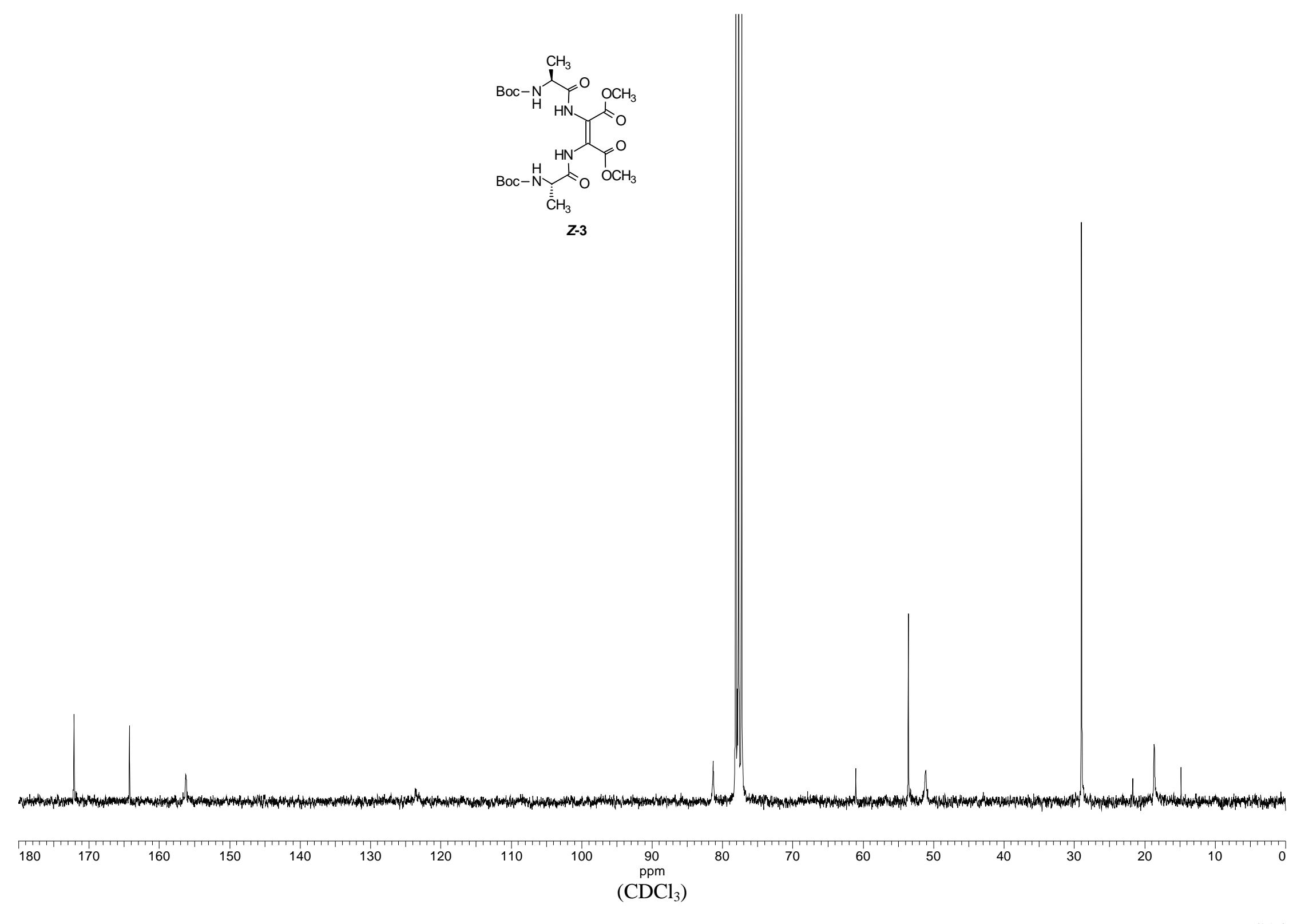




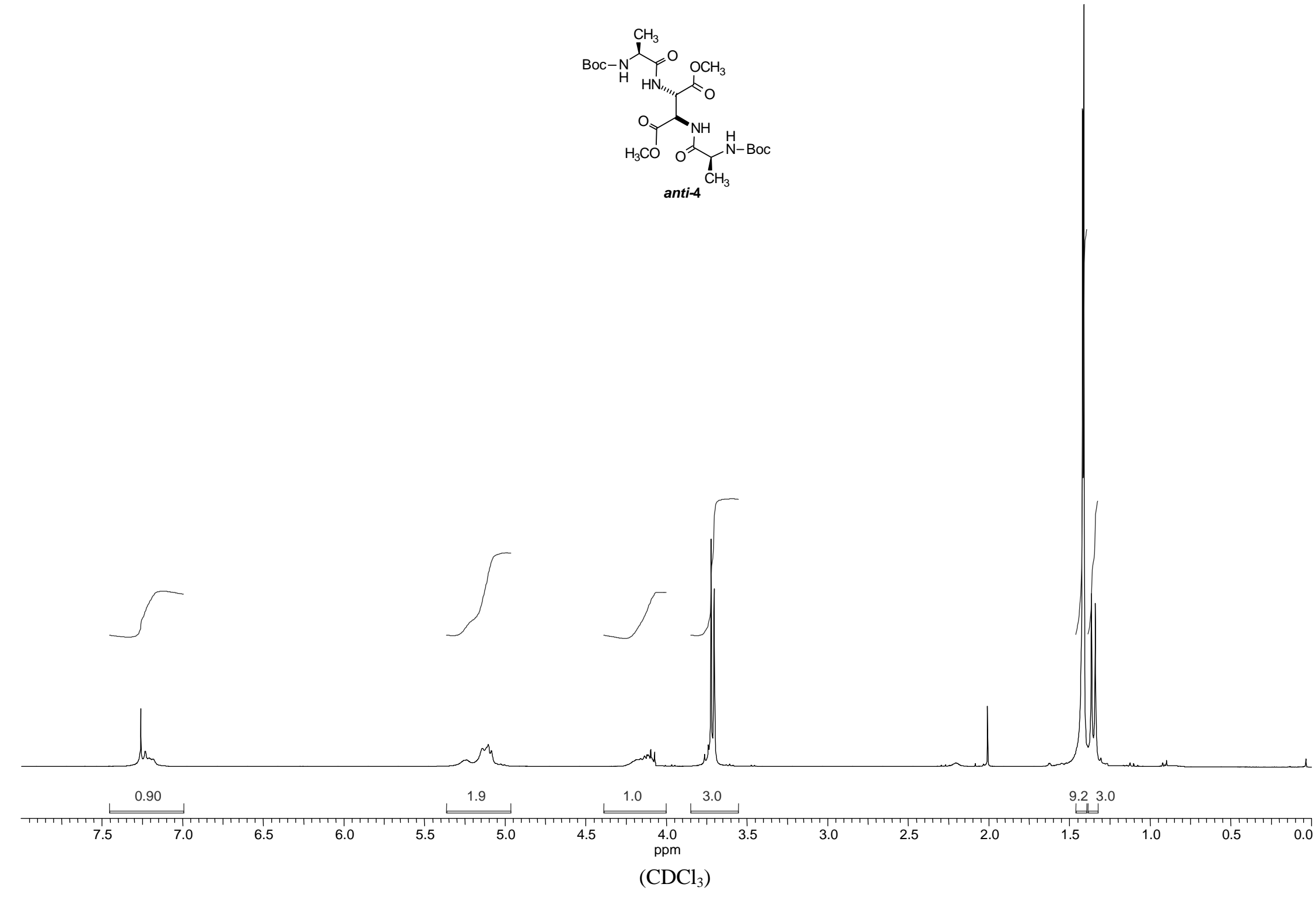




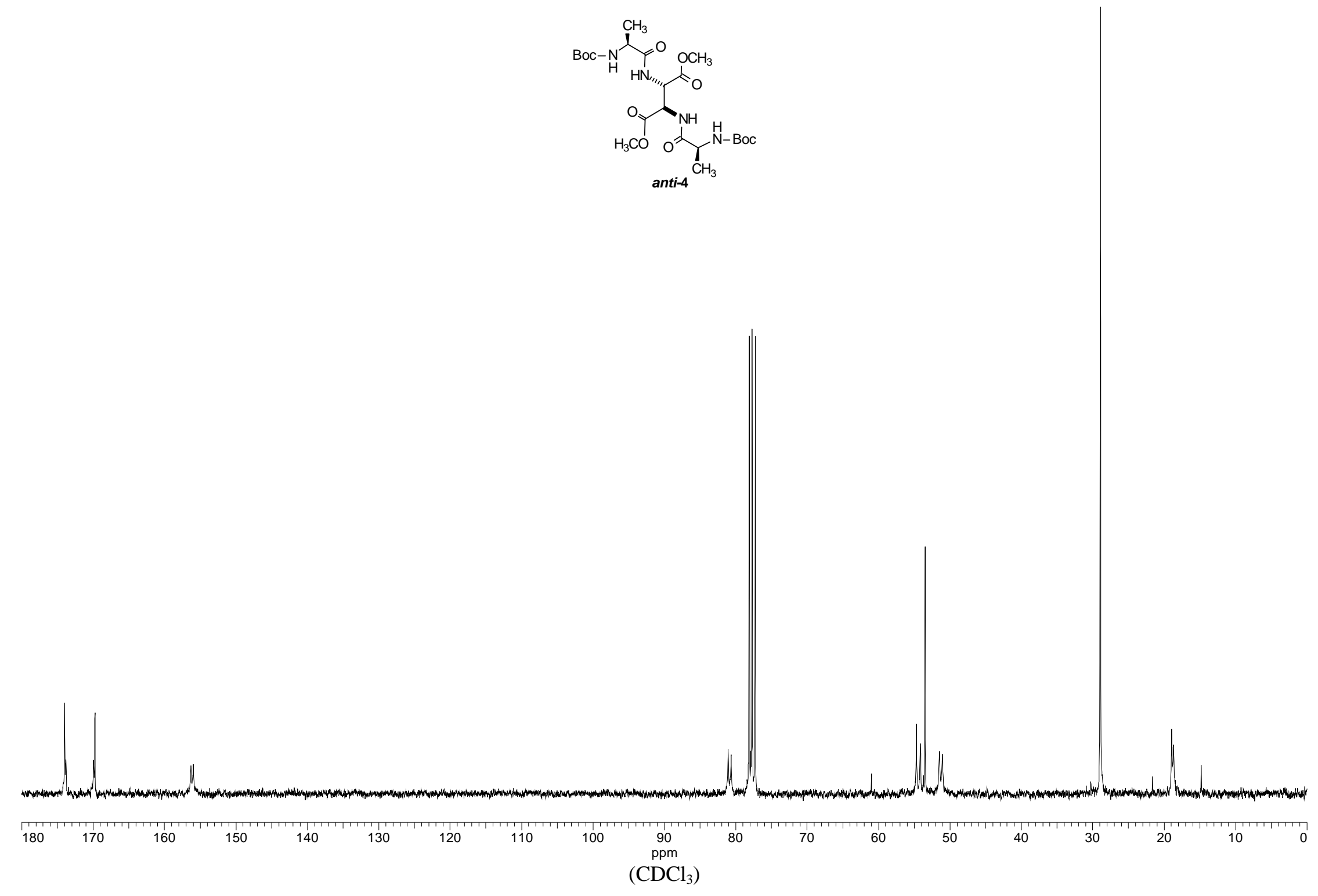




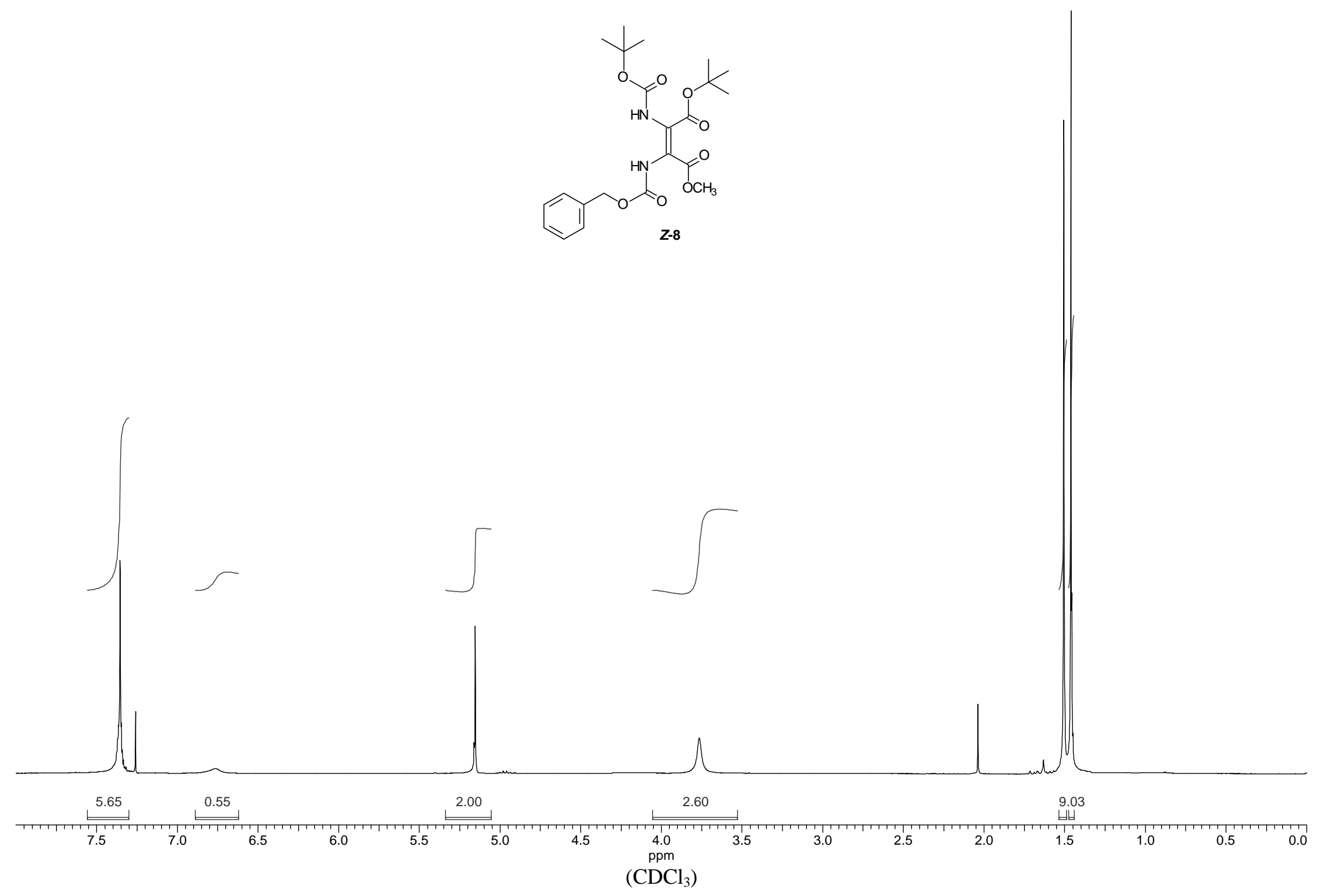




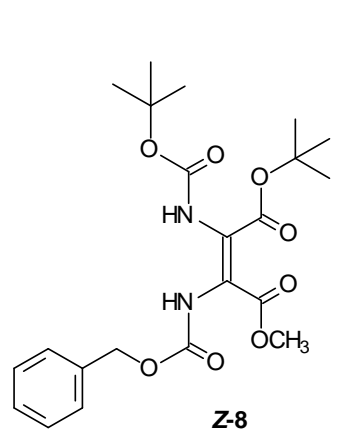

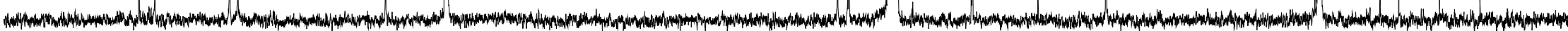
$180 \quad 170$
160 

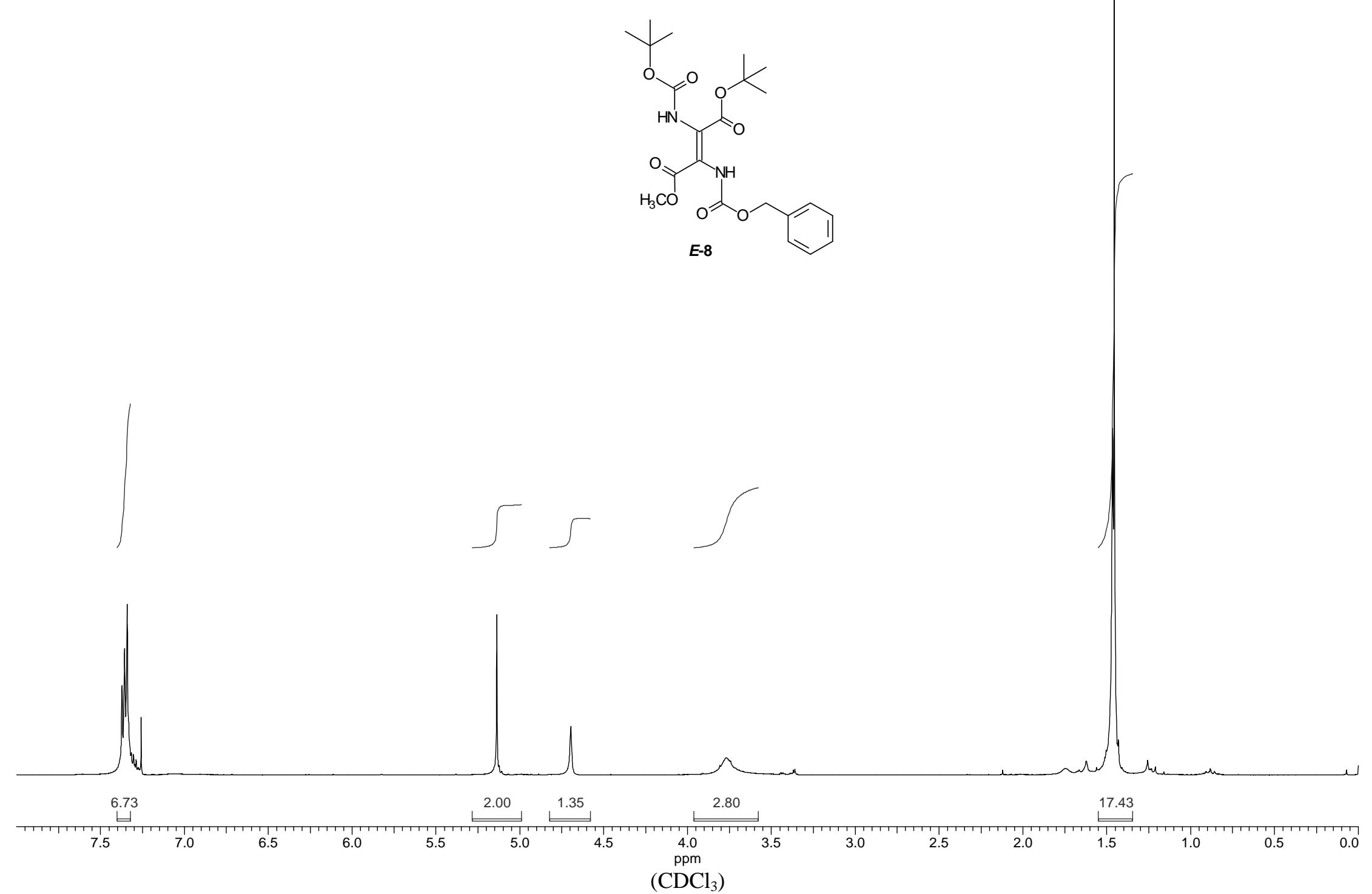


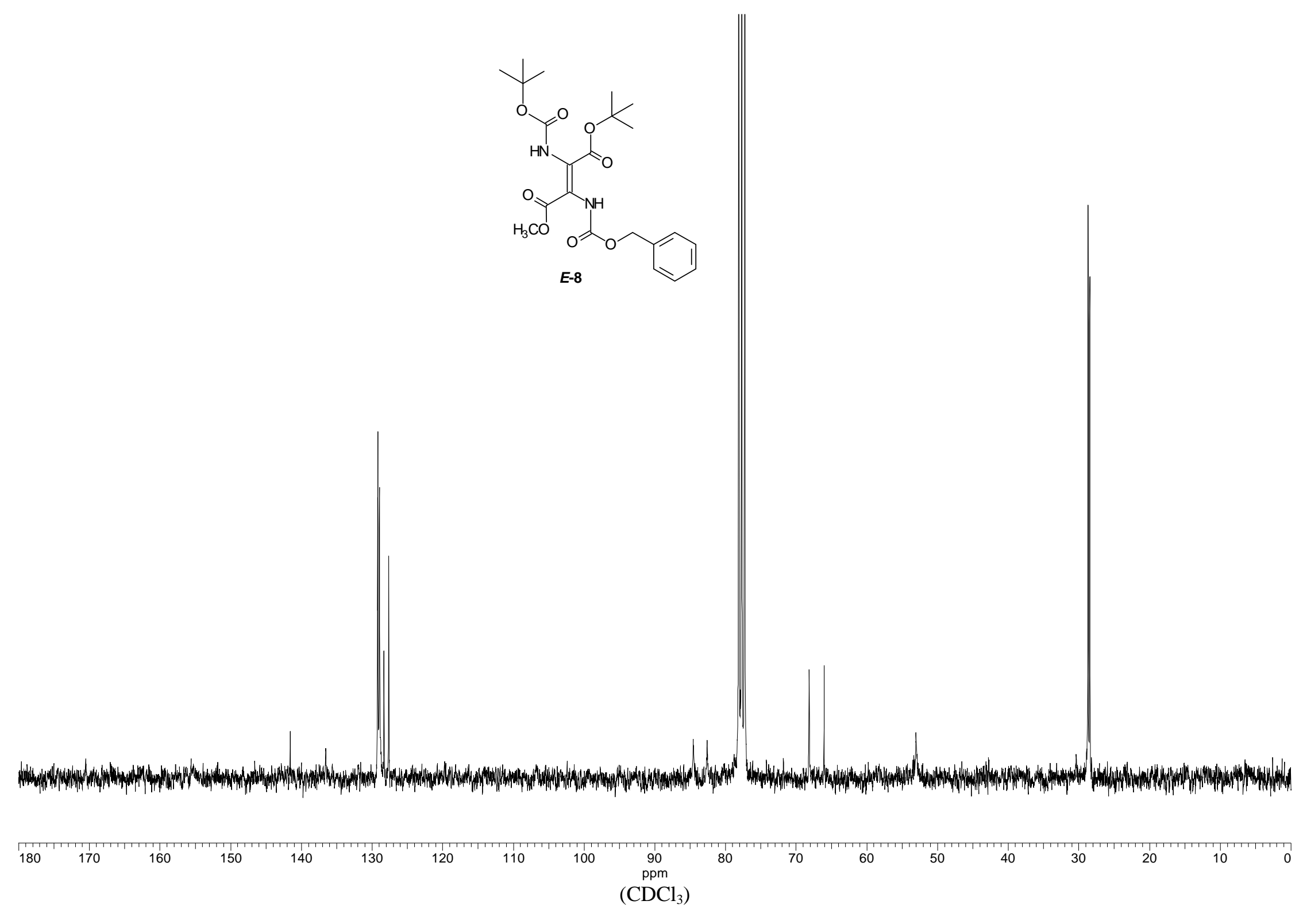




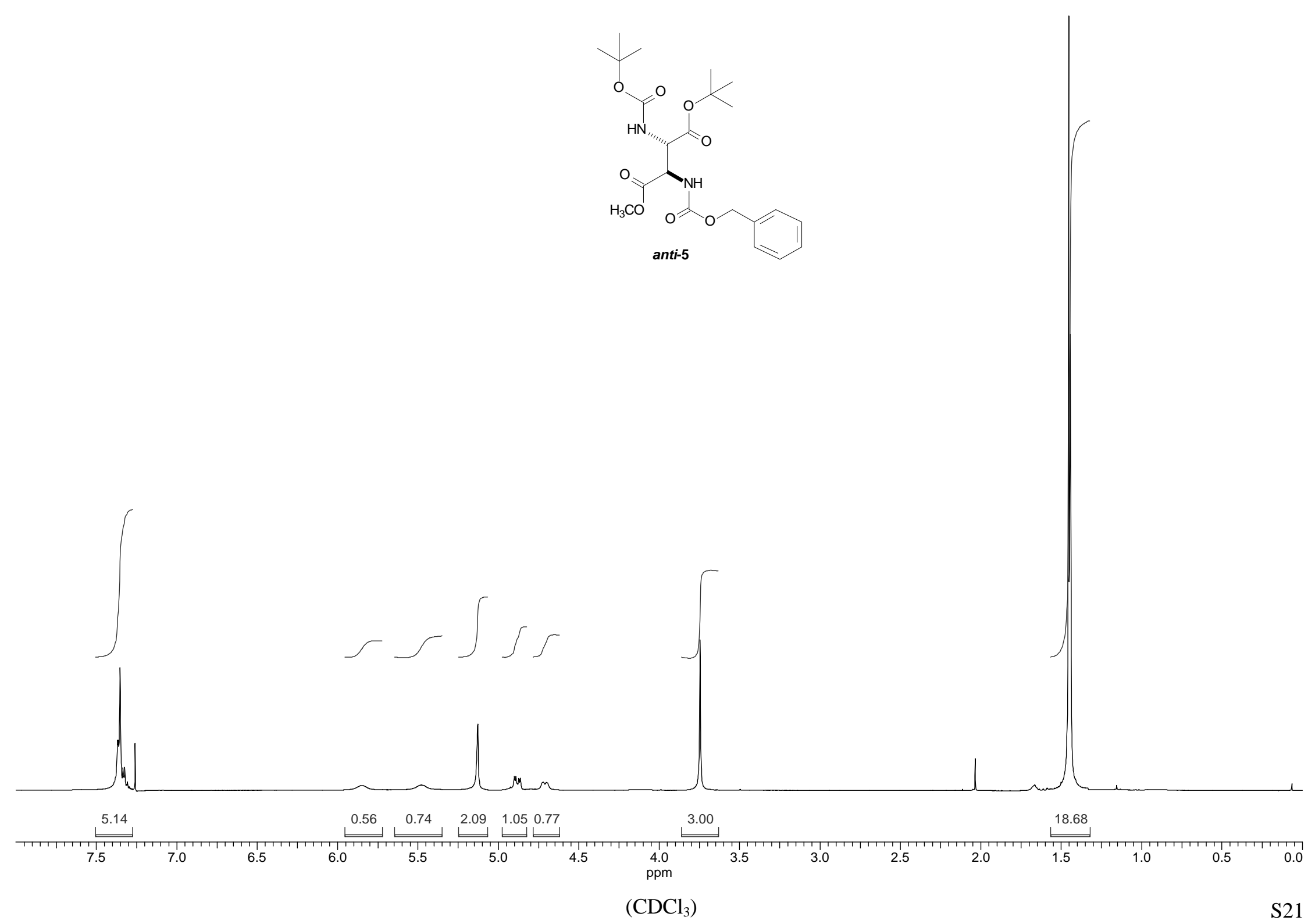




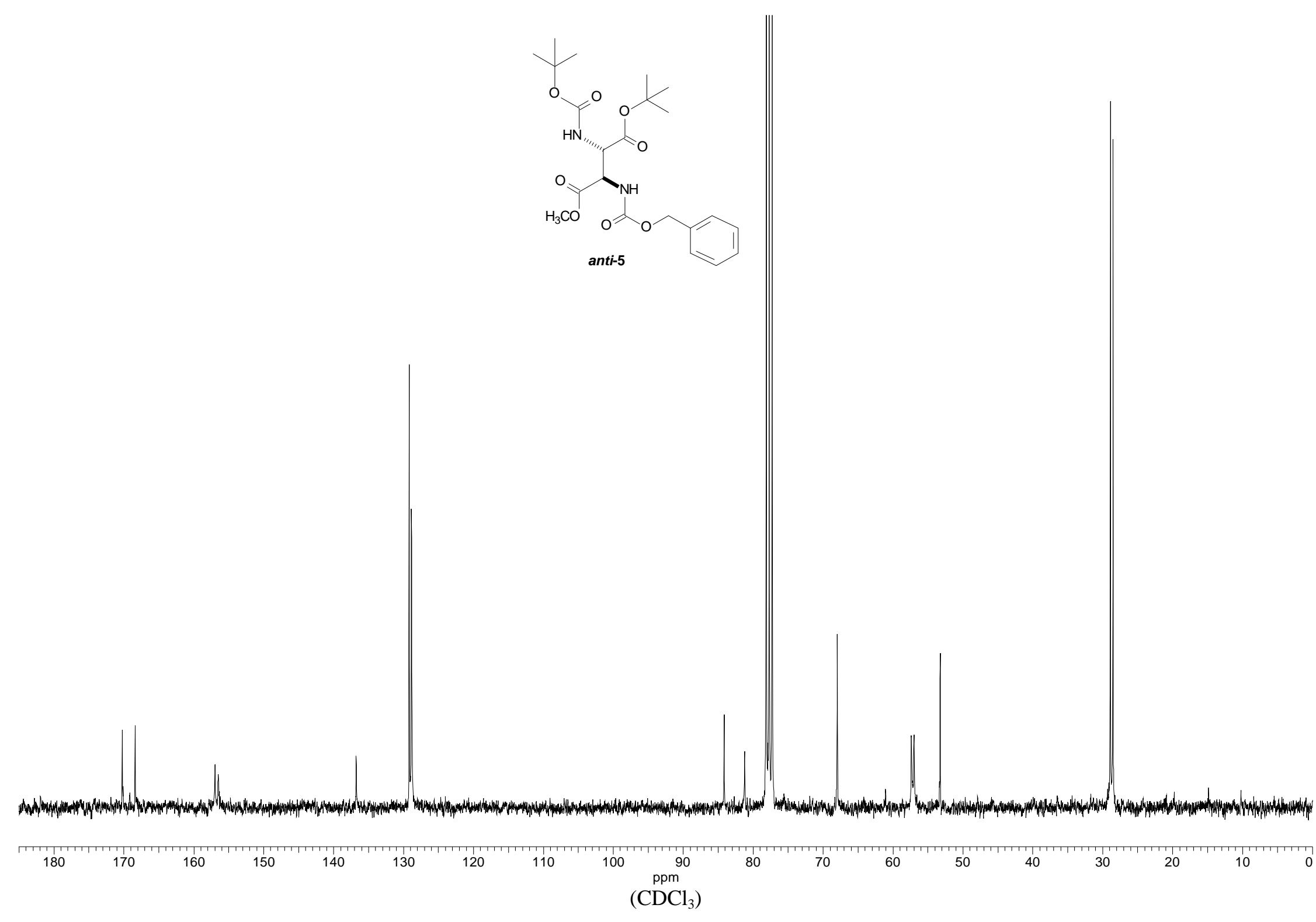



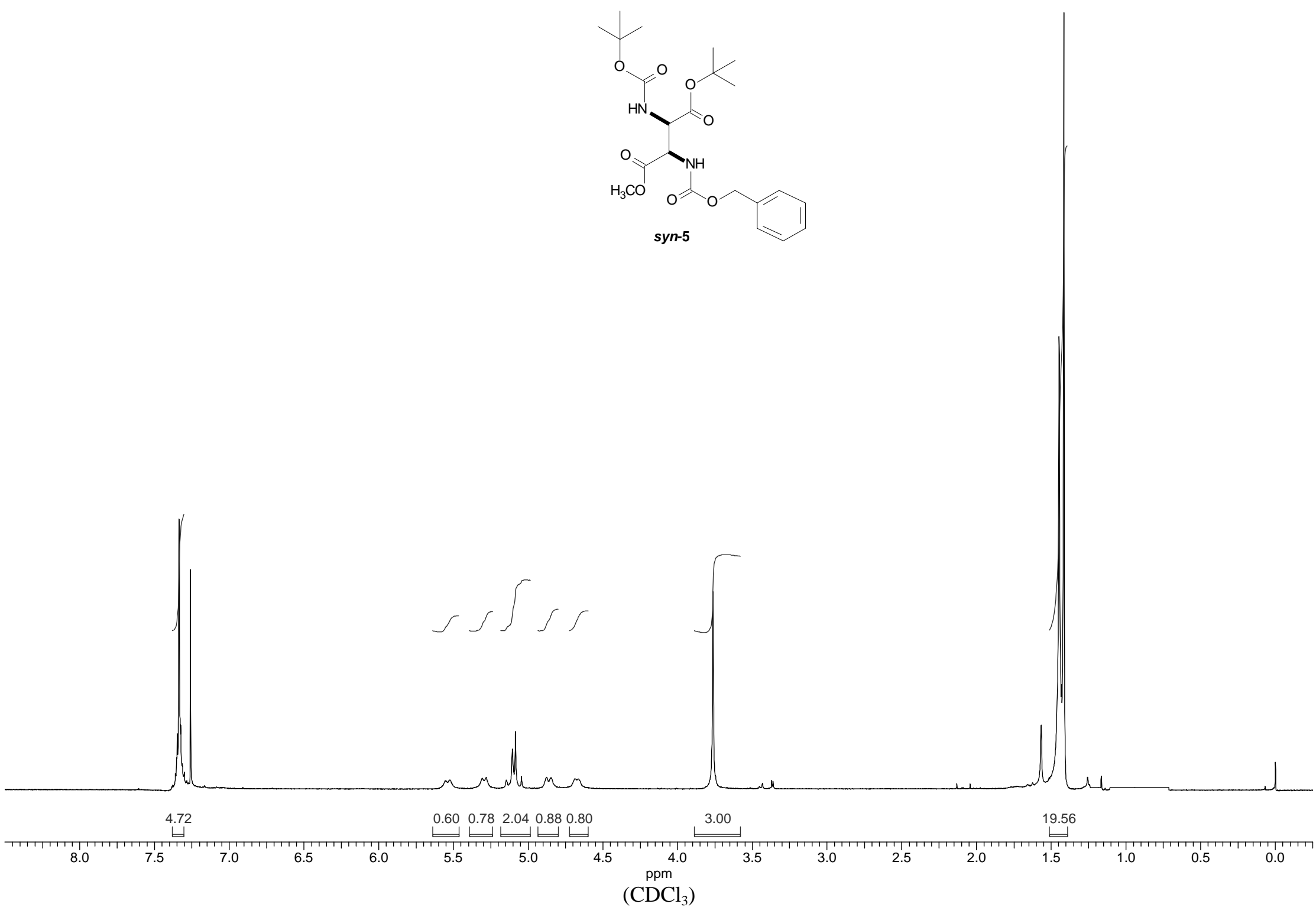


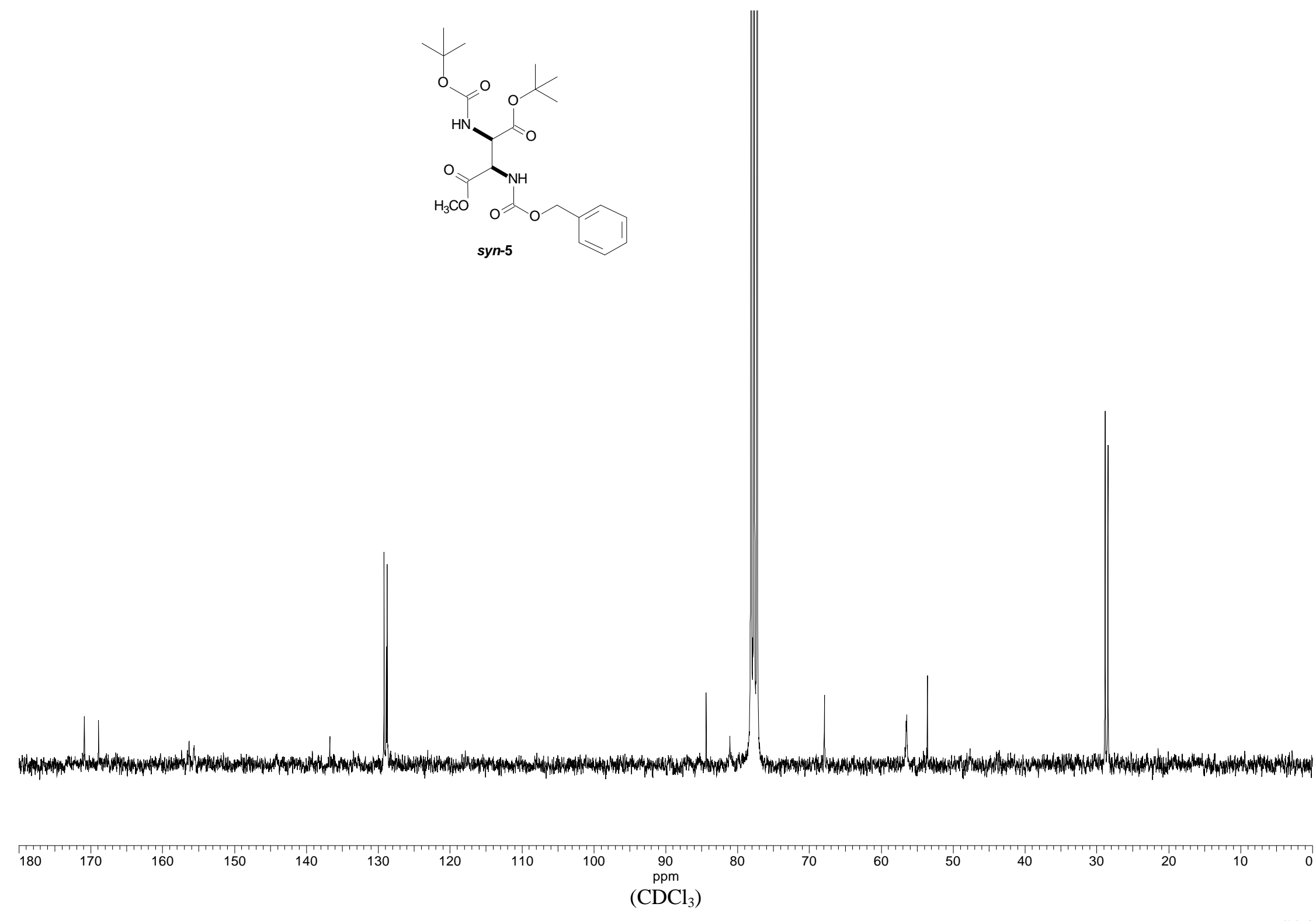

